Published in Journal of Hospitality \& Tourism Education, 2018, vol. 30, no. 1, pp. 11-18

which should be cited to refer to this work

DOI: https://doi.org/10.1080/10963758.2017.1413379

\title{
How to deal with amotivated students? Using commitment to reduce amotivation as applied to hospitality training
}

\author{
Lohyd TERRIER ${ }^{\mathrm{a}}$ - Lohyd.terrier@ehl.ch \\ Arthur RECH - $\underline{\text { Arthur.rech@ehl.ch }}$ \\ Benedicte MARFAING ${ }^{\text {- }}$ Benedicte.marfaing@gmail.com \\ Sebastien FERNANDEZ ${ }^{\mathrm{a}}$ - Sebastien.fernandez@ehl.ch
}

a Ecole hôtelière de Lausanne, HES-SO // University of Applied Sciences Western Switzerland

Le Chalet-à-Gobet, 1000 Lausanne 25, Switzerland

b Laboratoire de Psychologie, Université de Fribourg, Switzerland 


\begin{abstract}
:
Amotivation can be considered one of the more important problems hospitality training faces. This research paper aims to test if using commitment can reduce amotivation and increase performance in the context of training programs. We used action identification to improve the effectiveness of commitment. Ninety-two students participated in the experiment. Broken down into three experimental conditions, 29 participated in a standard training program and 63 in one of the two training programs using commitment (33 participants for the low identification-level commitment and 30 for the high). Results show that commitment increases performance and reduces amotivation. Furthermore, the link between the strength of participants' commitment and performance appears to be mediated by amotivation. Finally, results are discussed and future avenues of research are suggested.
\end{abstract}

\title{
Keywords:
}

Amotivation, Commitment, Hospitality, Training 


\section{Introduction}

Despite recent economic crises, the tourism and hospitality sectors continue to grow exponentially (Rynne, Kwek \& Bui, 2013). It is estimated that 69 million new jobs will be created in the hospitality industry to 2021. Among the multiple challenges that this development will entail, the hospitality workforce will have to be motivated and qualified to ensure operational success and high service quality. As such, academic training is a strategic element in disseminating the knowledge and skills that will enable hoteliers to face the challenges of tomorrow. This challenge is reflected in hotel companies' growing interest in students from hospitality schools (Dalbor \& Feinstein, 2001).

To rise to this challenge, trainers must motivate their students and foster a strong commitment to training. According to Rynne et al. (2013), bolstering students' motivation could help ensure that the tourism and hospitality managers of tomorrow are top-notch. Indeed, several research papers emphasize the importance of motivation in predicting performance during training sessions but also performance after training (Deci \& Ryan, 1985). Unfortunately, training programs often fail to motivate their participants and fall short of their goals in terms of skills development. For many trainers, inefficient training is primarily due to low motivation levels among participants (McFarlane, 2010). Therefore, it is essential to introduce tools to ensure sufficient levels of motivation in training.

The aim of this research is to test if using social influence tools, such as commitment strategies, can influence participants' motivation and performance in the context of a hospitality training program.

\section{Literature review}

\subsection{Motivation: A training objective?}


Many different definitions of the concept of motivation exist. For instance, Vallerand and Thill (1993, p. 428) define the concept of motivation as a "hypothetical construct to describe the internal and/or external forces that lead to the initiation, direction, intensity, and persistence of behavior". For Ryan and Deci (2000, p.54), "To be motivated means to be moved to do something (...) someone who is energized or activated toward an end is considered motivated.” Defined as a behavior driver, motivation is considered a key element in the success of a training initiative.

Among the many theoretical models dealing with motivation, the self-determination model (Deci \& Ryan, 1985, 2002) has enjoyed strong support for several years. According to this model (Deci \& Ryan, 2002), different forms of motivation are linked to the feeling of freedom associated with behavioral choices: intrinsic motivation, extrinsic motivation and amotivation. The more people feel responsible for their behavioral choices the more they tend to be intrinsically motivated. This form of motivation is related to internal factors such as satisfaction and pleasure derived from an activity. On the contrary, we are referring to extrinsic motivation when individuals are motivated by external factors such as the desire to obtain or avoid something (reinforcement or avoid a punishment). Finally, sometimes individuals are unable to make the connection between their actions and the results obtained. They believe that their behaviors are caused by factors beyond their control and do not feel motivated to perform them. This is known as amotivation. Amotivation corresponds to a lack of motivation to engage in a behavior. In other words, an amotivated person will be reluctant to follow the instructions of a trainer or the instructions given in the context of training. According to Jackson-Kersey and Spray (2015, p.3), “amotivation is a complete lack of self-determination and may result if the individual lacks competence, devalues the activity or is deficient in their abilities to achieve desired outcomes.” 
In a training context, amotivation is usually related to a lack of involvement and commitment from participants. Consequently, results of several studies show that this form of motivation is negatively linked to academic performance (Legault, Green-Demers \& Pelletier, 2006). For instance, amotivated students’ boredom is higher during classes (Vallerand \& Thill, 1993), stress perceived is higher while studying (Baker, 2004) and dropout rates are higher than regular students (Vallerand, Fortier \& Guay, 1997). Finally, Ntoumanis, Pensgaard, Martin and \& Pipe (2004) show that amotivation can also been associated with boredom, low attendance, and low involvement in physical education. Therefore, it is important to understand how amotivation can be reduced in the context of training.

\subsection{Commitment: a tool of influence}

Individuals generally try to be as consistent as possible in their commitments, choices and behaviors (Cialdini, 2007). Thus, many studies show that this need for consistency between opinions and behaviors is a powerful tool of influence (Cialdini, 2007; Cialdini \& Goldstein, 2004). For instance, Freedman and Fraser (1966) have shown that individuals who agreed to carry out a preparatory behavior (display a small sign for road safety in front of their home) were more likely to accept a subsequent and more burdensome target (install a large sign for road safety) than individuals exposed only to the large request. This result refers to the commitment theory (Kiesler \& Sakamura, 1966) whereby individuals are motivated to behave in a consistent manner, i.e. they are more likely to act in the same way as they had in the past. In other words, obtaining preparatory behaviors could significantly increase the likelihood that individuals subsequently accept to perform more important behaviors. In the study conducted by Freedman and Fraser (1966), the preparatory behavior (to accept to display a small sign) committed individuals in a behavioral way, which led them to accept to perform the target behavior (to accept a larger sign). This was done in order to stay consistent with past behavior (Cialdini, 2007). 
However, for a behavior to generate commitment, it must be done under conditions "in which an action can only be attributed to the person who carried it out” (Joule \& Beauvois, 1998 p.60). These conditions are 1) the characteristics of the act, 2) the reasons that have led the individual to perform it and 3) how the individual identifies the act. Thus, the more an act is visible and important the more it is committing (Girandola \& Joule, 2008). It must also be achieved freely, without invoking either a threat or the possibility of reinforcement. This sense of freedom will allow individuals to make the connection between their behaviors and their attitudes. Finally, several researchers (Girandola, 2003; Meneiri \& Gueguen, 2014) propose to use the concept of “action identification” to define the commitment level of a given behavior.

According to Vallacher and Wegner (1985), an action may be identified through different linguistic labels. Thus, an individual who is asked what he is doing, will reply with the linguistic label that seems best to account for the action he is performing. Therefore, the same action may be called by many linguistic labels (Meineri, Grandjean \& Guéguen, 2011). For instance, a person signing a petition in favor of the environment can identify his behavior in different ways: 1) he put his name on a piece of paper, or 2) he agrees to behave in accordance with the proposals included in the petition. These examples refer to different levels of identification (Vallacher \& Wegner, 1985). Low identification levels are concrete, descriptive, and describe how an action is effectively performed (Dar \& Katz, 2005); high identification levels are more abstract, and describe why an action is performed and the potential consequences (Dar \& Katz, 2005). In the context of a commitment strategy, the obtained behaviors can be identified at several levels.

According to Girandola (2003), 1) a high identification level of an action reinforces the commitment to this action and 2) commitment involved in an action increases the probability 
of attributing a high identification level to the action. Indeed, a strong commitment would result in "most salient or more available cognitions relating to the identification of the act" (Girandola, 2003, p.221). The work of Fointiat, Caillaud and Martinie (2004; Fointiat, 2006) tested these proposals directly. In this research paper, the researchers' goal was to obtain help behaviors from passersby (report the loss of a ticket or a scarf). To do this, passersby were first asked to perform a preparatory act (indicate a direction on a map). Once this action was performed, researchers manipulated the level of identification of this action by thanking them in several different ways: first, uttering - "It's clear" - had the effect of assigning a low level of identification with the preparatory behavior (concrete, description); while the second - "You're very helpful" - had the effect of assigning a higher level of identification (abstract reasons for the action). The results show that the higher the identification level of the preparatory act, the greater the effectiveness of the engagement strategy. According to Meineri et al. (2011), a high identification level offers a higher self-definition potential. By consequence, an individual performing an action with a high level of identification will be more motivated to stay consistent with this action because this action is more representative of him.

Several studies attest to the effectiveness of commitment strategies in various fields such as citizenship (Deschamps, Joule \& Gumy, 2005), environmental protection (Meineri \& Gueguen, 2014; Terrier \& Marfaing, 2015 ${ }^{\mathrm{ab}}$ ), performance (Girandola, 2003; Meineri et al., 2011) and training (Weiss, Girandola \& Colbeau-Justin, 2011).

On this basis, Joule (2002) proposes using commitment to improve the efficiency of conventional training programs. The training participants were unemployed individuals attending vocational training programs. The purpose of the training program was to introduce them to effective job search techniques. Participants were free (commitment) or forced (no commitment) to participate in the training program. The results show that participants freely 
choosing to take the training class show more interest and satisfaction with the program, are more involved and retain the content of the training courses more effectively. They also take better advantage of best practices and knowledge they receive. Consequently, their job searches are more active and effective. Indeed, in this group, 56\% of the unemployed individuals found a job after the training program compared with only $26 \%$ of unemployed individuals who were not committed during the training program.

More recently, Weiss et al. (2011) have used a commitment strategy during a training program dedicated to increasing safety behaviors in the event of a natural disaster. To this end, participants were asked to perform a preparatory act: they had to agree, by raising their hands, to perform both at home and at work a task involving the identification of the danger (locate warning signs, etc.). In order to ensure commitment, they were free to accept or decline to perform the preparatory act. This training program was compared to a more conventional training program without a preparatory act. Results show that the use of commitment increases the effectiveness of training, as evidenced by the continued increase in safety behaviors in the group with commitment.

Thus, the use of commitment contributes to improving the participants' performance during professional training programs. The aim of our research is to extend the results of research using commitment to hospitality academic training but also to study the effect of commitment on participants' amotivation. More concretely, we propose to test 1) if commitment can reduce the amotivation level of hospitality training participants and 2) if amotivation reduction can increase training performance. To this end, we will manipulate the commitment level by modifying the action identification level. Accordingly, the hypotheses are listed as follows:

Hypothesis 1a. Training using commitment should reduce the participants' level of amotivation more than conventional training. 
Hypothesis 1b. Furthermore, we hypothesize that as commitment level increases the level of amotivation will decrease. In other words, training using commitment should reduce the participants' level of amotivation when it uses a high action identification level more than when it uses a low action identification level.

Several authors (Girandola, 2003; Meneiri et al., 2011) consider the aim of training to be to increase participants’ performance. On this basis, we can formulate the following hypotheses:

Hypothesis 2a. Training using commitment should produce higher performance gains than conventional training.

Hypothesis 2b. On this basis, we can formulate the hypothesis that the higher the identification level, the greater the performance gains associated with training will be. In other words, training using commitment should produce higher performance gains when it uses a high action identification level than when it uses a low action identification level.

Hypothesis 3. Finally, considering motivation as a key element of performance, we hypothesize that the amotivation reduction could mediate the link between commitment and performance.

\section{Method}

\subsection{Participants}

Ninety-two students from a hospitality management school participated in the experiment (47 women, 45 men, 18 to 28 years old). Research was conducted during a three-day housekeeping training class.

\subsection{Procedure}


This research paper uses a control condition and two experimental conditions. Under the control condition (CC), no commitment was applied: students participated in a conventional training program. Under the experimental conditions, a commitment was added to the training program. The strength of commitment was defined by manipulating the identification level of the commitment (low versus high). The experiment was conducted in three stages.

Step 1. Before the start of the housekeeping training class, all participants were assessed by the trainer. The assessment allows us to determine the initial level of participants' performance. The assessment was the same for all the conditions of the experiment.

Step 2. Once the assessment of performance was completed, the trainer asked participants exposed to the experimental conditions to sign a document whereby they committed to being actively involved during the training program. Participants were free to accept or reject this request (but all of them accepted). This preparatory act - to sign a contract of commitment - should increase participants' commitment by allowing them to take an active role in the training program. The identification level of this preparatory act was manipulated by changing the content of the contract according to the experimental conditions ${ }^{1}$.

The message in the low identification-level commitment condition was:

This contract testifies my commitment to actively participate in housekeeping training.

By this, I pledge to follow the guidelines that will be transmitted to me in this course and to respect the instructions given by the teacher.

On the contrary, the message in the high identification-level commitment condition was:

\footnotetext{
${ }^{1}$ It was done by following the procedure designed by other scholars (Dar \& Katz, 2005 ; Vallacher \& Wegner, 1985).
} 
This contract testifies my commitment to actively participate in housekeeping training.

By this, I pledge to develop subject-specific skills that are essential to complete my studies at (name of the school) and to respect the instructions given by the teacher

Step 3. At the end of the training session, participants' performance was again measured using the same criteria as in the initial assessment. Comparing pre- and post-training performance scores allows us to assess the performance increase. Finally, all participants answered a questionnaire about their motivation following training.

\subsection{Measures}

Training performance: Participants' performance was assessed by the trainer through 18 criteria measured on a scale from 1 to 6 (1 being the lowest rating, 6 the maximum). We used the same evaluation criteria that were used in the housekeeping course, such as technical and operational skills (ability to follow procedures or effective use of equipment). Performance was assessed at the beginning and the end of the training session. The internal consistency of the evaluation was good with regard to both the pre-training and post-training (respectively, $\alpha=.95$ and $\alpha=.94)$. The first assessment's mean score was subtracted from the second assessment's mean score to obtain a measure of the performance increase. Thus, the higher the score, the higher the performance gain. This procedure was done in order to control for initial levels of performance that could be different between conditions.

Motivation: We used the amotivation scale of the Academic Motivation Scale (Vallerand, Blais, Brière \& Pelletier, 1989) to assess amotivation (Deci \& Ryan, 1985, 2002). Participants have to answer the question "Why are you participating in this course?" by positioning them on 4 items with a 7-point scale ranging from 1 "strongly disagree" to 7 "strongly agree” (items were: Honestly I don't know, I really feel that I'm wasting my time in this course; I once had good reasons to participate, however, now I wonder whether I should continue; I can't see why 
I came here anymore, and frankly, I couldn't care less; I don't know; I don't understand what I am doing in this class. $\alpha=.85$ ). The higher the score, the higher the participants feel amotivation.

\section{Results}

Of the 92 participants in this study, 29 participated in the conventional training program and 63 in one of the two training programs using commitment (33 participants for the low identification-level commitment condition and 30 for the high). In our sample, the pre-training performance test was 4.539 ( $\mathrm{SD}=0.453$ ), and the post-training performance was 5.150 $(S D=0.348)$. The average performance increase was $0.611(S D=0.354)$. The average score of amotivation was 1.130 ( $\mathrm{SD}=0.356)$. We used a t-test to test our first two hypotheses.

Regarding our first hypothesis, participants using commitment show an amotivation level that is significantly lower than that of the participants of the training without commitment (respectively, $\mathrm{M}=1.075, \mathrm{SD}=0.332$ versus $\mathrm{M}=1.250, \mathrm{SD}=0.383, t(90)=2.230, p<.05$; see Table 1). Moreover (H1b), participants in the high identification-level commitment condition were less amotivated than participants exposed to the low identification-level commitment condition (respectively $\mathrm{M}=1.000, \mathrm{SD}=0.000$ versus $\mathrm{M}=1.144, \mathrm{SD}=0.450, t(61)=1.747, p=.08$; see Table 1). However, this difference is not significant.

In accordance with our second hypothesis, the performance increase linked to training was significantly higher in the training sessions using commitment than in the regular training program (respectively $\mathrm{M}=0.705, \mathrm{SD}=0.315$ versus $\mathrm{M}=0.405, \mathrm{SD}=0.352, t(90)=-4.087, p<.001$; see Table 2). We can also see that the performance of participants exposed to the high identification-level commitment condition increased more than the performance of participants in the low identification-level commitment condition (respectively $\mathrm{M}=0.825$, $\mathrm{SD}=0.196$ versus $\mathrm{M}=0.596, \mathrm{SD}=0.363, t(61)=-3.064, p<.01$; see Table 2$)$. 
Finally, we used Baron and Kenny’s method (1986) to test if amotivation mediated the effect of commitment on performance (See Figure 1). Consequently, we have tested relationships between the target variables to establish a basis for testing mediation. Linear regressions showed that commitment had a significant negative effect on amotivation $(\beta=-.175, \mathrm{t}(91)=-$ 2.230, $\mathrm{p}<.05)$ and performance increase $(\beta=.300, \mathrm{t}(91)=4.087, \mathrm{p}<.001)$. A third regression analysis established that amotivation was a significant predictor of performance increase $(\beta=-$ $.277, \mathrm{t}(91)=-.279, \mathrm{p}<.01)$. Finally, when performance increase was regressed onto both commitment and amotivation, commitment effect was reduced $(\beta=.266, \mathrm{t}(81)=3.582, \mathrm{p}<.01)$.

Finally, we used a Sobel test (1982) of the reduction in the commitment effect to show a partial mediation of amotivation of the link between commitment and performance increase $(Z=1.509, p=.06)$. This mediation effect is marginally significant. Thus, it seems that participating in a training course using commitment could decrease the level of amotivation, which generates a performance increase.

\section{Discussion}

The objective of this research paper was to measure the effectiveness of a training program using commitment on participants' motivation and performance. We wanted to improve training's effectiveness by reducing participants' amotivation. To do this, we asked participants to perform a preparatory behavior: to sign a contract committing them to actively participate in the training course. For some participants, this behavior was a high identification level behavior, while for the others it was a low identification level behavior. A third group of participants attended a conventional training class without performing a preparatory behavior.

The results confirmed our hypotheses for the most part. Indeed, we demonstrated that the training class with the commitment aspect had a larger effect on participants' performance 
than the regular training session. These results are in line with other studies in which commitment was used as a persuasive tool (Meineri et al., 2011). Moreover, if Meineri et al. (2011) essentially assessed an attitudinal impact of commitment on training, we were focused more on the direct aspect of commitment's effectiveness: performance. Indeed, our results show that it is more effective to use a high identification preparatory behavior to increase performance than to use a low identification preparatory behavior. This confirms that a high identification level is an efficient way to increase the committing nature of a behavior (Girandola, 2003). On this basis, we can propose that the performance increase related to training - not only involvement and satisfaction - could be linked to the committing character of this training program.

Moreover, according to our hypotheses, commitment reduces the participants' amotivation level. Indeed, participants are less amotivated when a training program uses commitment than when it does not. However, although commitment reduces amotivation, our manipulation of the commitment level by action identification does not impact amotivation level. More precisely, while participants in the high identification-level commitment condition were less amotivated than those in the low identification-level commitment condition, the difference was not significant.

Nevertheless, as the commitment reduced the amotivation level and increased participants' performance, we tried to specify the relationship between these variables. Results showed that the effect of commitment on performance increase could be mediated by the amotivation level, as the mediation effect is very nearly significant. We therefore propose that the use of commitment strategies could, by reducing amotivation, increase participants’ performance and, consequently, increase training's effectiveness. These results represent a major opportunity for training classes, whether academic or organizational. Indeed, trainers seek to avoid at all costs 
participants' amotivation (Legault et al., 2006; Vallerand et al., 1997). Commitment could be considered as a useful tool in preventing high amotivation levels and thus enhance participants' performance.

In terms of managerial implications, our results support the proposition of Joule and Beauvois (1998, p.93) that: "to admit that a commitment in an act is also a commitment to an identified act $[\ldots]$ has serious consequences in terms of practice, the trainer must be sure that the acts he has managed to obtain are identified at the right identification levels." Indeed, the same preparatory act may, depending on the level of identification of the action with which it is associated, lead to different results. Here, the manipulation of the action identification level allowed us to act on the level of performance, and at the same, on the effectiveness of the training program. From an operational point of view, these results are important because they point out that the most important element of a committing strategy is not only the behavior, but also the representation that the individual has of this behavior.

In addition, the use of commitment provides significant effects, in terms of motivation as it translates to performance, using very simple tools. Indeed, signing a commitment contract requires only a very limited investment in terms of time and effort from the trainer and the participant. Moreover, in our research no participant refused to sign the contract. Finally, manipulation of the levels of identification is not complicated and is done by manipulating the statement of commitment (again, this operation has no impact on the acceptance or refusal to sign the contract). This manipulation of commitment differs from other research using commitment (Joule \& Beauvois, 1998; Herbout, Guéguen \& Grandjean, 2008), which uses more burdensome tools. It is an important aspect because a major drawback of commitment strategies is the time and/or energy required (Meineri et al., 2001). Consequently, it is important 
and easy for trainers to insert commitment procedures in their training program. Indeed, even if results on amotivation are limited, effects on performance are substantial.

\section{Limitations}

A major limitation of this research is related to its sample. Indeed, participants are students, which could pose problems in terms of the generalization of these results to a professional training context. Nevertheless, the results of Meineri et al. (2011) were obtained in a professional context and also show a significant improvement in the effectiveness of training that mobilizes commitment. Furthermore, the housekeeping class was specifically designed as a professional training program whose aim was more operational than theoretical in nature. Finally, it is a three-day course similar to a professional training session that could be found in a company.

According to Cialdini (2007), different factors contribute to generating commitment. In this research, we have used the identification level of action as a commitment factor. Indeed, in line with Meineri et al. (2011; Meneiri \& Gueguen, 2014), our results show that a commitment offers a higher performance gain with a high level of identification (abstract, describing why an action is performed) than with a low level (concrete, describing how an action is performed). Future research should test to determine which commitment factors are the most effective in improving performance during training programs. They should also test whether the combination of several commitment factors generates more impact on performance. It would, for example, be easy to manipulate the visibility of the document by displaying (or not displaying) the participant's commitment contract. In addition, the use of free choice, as used by Joule (2002), could also be easily implemented.

In conclusion, our results support the proposition that a committing communication strategy could, by increasing participants' performance, improve the effectiveness of 
training. This finding obviously deserves to be developed and calls for further research that could clarify the conditions under which the commitment has a significant impact on participants’ motivation.

\section{Conclusion}

The struggle against amotivation is one of the most important challenges for trainers. Indeed, letting amotivation to spread in a training situation can lead to a variety of risks including reduced involvement and lower performance following the training session.

We proposed, in this research, to combine tools from research on commitment to the context of hospitality training in an academic setting. The results clearly show that the use of commitment tools reduces participants' amotivation in training situations. They also show that reducing participants' amotivation could enable them to benefit more from the training course, which results in higher performance gains. Finally, we observe that the level of identification of the action is an important commitment factor whose effects significantly impact performance. These results open the door to further research mobilizing commitment in the aim of improving the effectiveness of training by acting on participants' motivation levels. 


\section{References}

Baker, S. R. (2004). Intrinsic, extrinsic, and amotivational orientations: Their role in university adjustment, stress, well-being, and subsequent academic performance. Current Psychology, 23(3), 189-202.

Baron, R. M., \& Kenny, D. A. (1986). The moderator-mediator variable distinction in social psychological research: Conceptual, strategic and statistical considerations. Journal of Personality and Social Psychology, 51, 1173-1182.

Cialdini, R. B. (2007). Influence: The Psychology of Persuasion, New York: HarperCollins.

Cialdini, R. B., \& Goldstein, N. J. (2004). Social influence: Compliance and conformity. Annual Review of Psychology, 55(1), 591-621.

Dalbor, M.C., \& Feinstein, A. H. (2001). Was Thomas Jefferson Trained for His Profession? The Learned versus Trained Hospitality Student. Journal of Hospitality \& Tourism Education, 13(1), 25-28.

Dar, R., \& Katz, H. (2005). Action identification in obsessive-compulsive washers. Cognitive Therapy and Research, 29(3), 333-341.

Deci, E. L., \& Ryan, R. M. (1985). Intrinsic motivation and self-determination in human behavior. Springer Science \& Business Media.

Deci, E., \& Ryan, R. (Eds.), (2002). Handbook of self-determination research. Rochester, NY: University of Rochester Press. 
Deschamps, J. C., Joule, R. V., \& Gumy, C. (2005). La communication engageante au service de la réduction de l'abstentionnisme électoral : une application en milieu universitaire. European Review of Applied Psychology, 55(1), 21-27.

Fointiat, V. (2006). "you're helpful" versus "that's clear". Social versus functional label in the foot-in-the-door paradigm. Social Behavior and Personality, 34(5), 461-466.

Fointiat, V., Caillaud, J., Martinie, M.-A. (2004). Etiquetage social vs étiquetage fonctionnel: Quels effets sur le pied-dans-la-porte avec demande implicite? Revue européenne de psychologie appliquée, 54, 273-278.

Freedman, J. L., \& Fraser, S. C. (1966). Compliance without pressure: the foot-in-the-door technique. Journal of Personality and Social Psychology, 4(2), 195-202.

Girandola, F. (2003). Psychologie de la persuasion et de l'engagement (Vol. 4). Presses Universitaire de Franche-Comté.

Girandola, F., \& Joule, R.-V. (2012). La communication engageante : aspects théoriques, résultats et perspectives. L'Année psychologique, 112, 115-143.

Herbout, V., Guéguen, N., Grandjean, I. (2008). Foot-in-the-door application in organization: How employees could be more effective? European Journal of Scientific Research, 21(4), 729-735.

Jackson-Kersey, R., \& Spray, C.M. (2015). The effect of perceived psychological need support on amotivation in physical education, European Physical Education Review, 21(4), 1-14.

Joule, R.-V., Beauvois, J.-L. (2002). Petit traité de manipulation à l'usage des honnêtes gens. Grenoble: PUG.

Joule R. V., \& Beauvois J. L. (1998) La soumission librement consentie : comment amener les gens librement ce qu'ils doivent faire ? Presses universitaires de France.

Kiesler, C. A., \& Sakumura. J. (1966). A test of a model for commitment. Journal of Personnality and Social Psychology, 3(3), 349. 
Legault, L., Green-Demers, I., \& Pelletier, L. G. (2006). Why do high school students lack motivation in the classroom? Toward an understanding of academic amotivation and the role of social support. Journal of Educational Psychology, 98(3), 567.

McFarlane, D.A. (2010). Teaching unmotivated andunder-motivated college students: Problems, challenges, and considerations. College Quarterly, 13(3), 1-5.

Meineri, S., Grandjean, I., \& Guéguen, N. (2011). Effets d'une procédure incitative associée à une identification de l'action sur des comportements et attitudes professionnelles de salariés. Psychologie du Travail et des Organisations, 17.

Meineri, S., \& Gueguen, N. (2014). Foot-in-the-door and action identification : Binding communication applied to environmental conservation. European Review of Applied Psychology, 64 (1), 3-11.

Ntoumanis, N., Pensgaard, A. M., Martin, C., \& Pipe, K. (2004). An ideographic analysis of amotivation in compulsory school physical education. Journal of Sport and Exercise Psychology, 26, 197-214

Ryan, R., \& Deci, E. (2000). Self-determination theory and the facilitation of intrinsic motivation, social development, and well-being. American Psychologist, 55(1), 68-78.

Rynne, J., Kwek, A., \& Bui, J. (2013). Insights into the academic motivation of tourism and hospitality students in a research methods course. Journal of Hospitality \& Tourism Education, 24(2-3), 28-39.

Sobel, M. E. (1982). Asymptomatic confidence intervals for indirect effects in structural equation models. Socialogical Methodology, 13, 290-312.

Terrier, L., \& Marfaing, B. (2015) ${ }^{\mathrm{a}}$. Using binding communication to promote conservation among hotel guests. Swiss Journal of Psychology, 74(3), 169-175. 
Terrier, L., \& Marfaing, B. (2015) ${ }^{\mathbf{b}}$. Using social norms and commitment to promote proenvironmental behavior among hotel guests. Journal of Environmental Psychology, 44, 1015.

Vallacher, R. R., \& Wegner, D.M. (1985). A theory of action identification. London: LEA.

Vallerand, R. J., Blais, M. R., Brière, N. M., \& Pelletier, L. G. (1989). Construction et validation de l'échelle de motivation en éducation (EME). Canadian Journal of Behavioural Science/Revue canadienne des sciences du comportement, 21(3), 323.

Vallerand, R. J., Fortier, M. S., \& Guay, F. (1997). Self-determination and persistence in a reallife setting: toward a motivational model of high-school dropout. Journal of Personality and Social Psychology, 72(5), 1161.

Vallerand, R. J., \& Thill, E. E. (1993). Introduction à la psychologie de la motivation. (L. é. inc., Éd.) Montréal: Vigot.

Weiss, K., Girandola, F., \& Colbeau-Justin, L. (2011). Les comportements de protection face au risque naturel: de la résistance à l'engagement. Pratiques Psychologiques, 17(3), 251262. 